OPEN ACCESS

Edited by:

Turid Hellevik,

University Hospital of North Norway,

Norway

Reviewed by: Yuanzeng Min,

University of Science and Technology of China, China

M. Saeed Sheikh,

Upstate Medical University,

United States

${ }^{*}$ Correspondence:

Jian-Guo Sun

sunjg09@aliyun.com

Rong-Xia Liao

liaorx@aliyun.com

${ }^{\dagger}$ These authors have contributed equally to this work

Specialty section:

This article was submitted to

Radiation Oncology,

a section of the journal

Frontiers in Oncology

Received: 19 April 2021

Accepted: 18 August 2021

Published: 10 September 2021

Citation:

Niu K, Chen XW, Qin Y, Zhang LP,

Liao RX and Sun JG (2021)

Celecoxib Blocks Vasculogenic

Mimicry via an Off-Target Effect to

Radiosensitize Lung Cancer

Cells: An Experimental Study.

Front. Oncol. 11:697227.

doi: 10.3389/fonc.2021.697227

\section{Celecoxib Blocks Vasculogenic Mimicry via an Off-Target Effect to Radiosensitize Lung Cancer Cells: An Experimental Study}

\author{
Kai Niu ${ }^{1 \dagger}$, Xie-Wan Chen ${ }^{1,2 \dagger}$, Yu Qin ${ }^{3}$, Lu-Ping Zhang ${ }^{1}$, Rong-Xia Liao ${ }^{2 *}$ \\ and Jian-Guo Sun ${ }^{1 *}$ \\ ${ }^{1}$ Cancer Institute of Chinese People's Liberation Army (PLA), Xinqiao Hospital, Army Medical University, Chongqing, China, \\ ${ }^{2}$ Medical English Department, College of Basic Medicine, Army Medical University, Chongqing, China, ${ }^{3}$ Nutrition and Food \\ Hygiene Department, Institute of Military Preventive Medicine, Army Medical University, Chongqing, China
}

The resistance to radiotherapy in lung cancer can be attributed to vasculogenic mimicry (VM) to some extent. Celecoxib (CXB), a selective inhibitor of cyclooxygenase-2 (COX-2), is reported as a radiosensitizer in non-small cell lung cancer (NSCLC). However, whether CXB can regulate VM formation via an off-target effect to radiosensitize NSCLC remains unclear. This study aimed to elucidate the mechanism underlying the radiosensitizing effect of CXB on NSCLC, i.e., whether CXB can inhibit VM formation via binding to newly identified targets other than COX-2. CXB radiosensitivity assay was performed in BALB/C mice bearing $\mathrm{H} 460$ xenografts and $\mathrm{C} 57$ mice bearing Lewis lung cancer (LLC) xenografts, which were divided into the control, CXB, irradiation $(\mathrm{IR})$ treatment, and IR plus CXB groups. VM formation was observed using 3D Matrigel, periodic acid solution (PAS) staining, and immunofluorescence staining. The potential off-targets of CXB were screened using Protein Data Bank (PDB) database, MGLTools 1.5.6, and AutoDock Vina 1.1.2 and confirmed by Western blotting, enzyme activity assay, and RNA interference in vitro experiments and by immunohistochemistry in vivo experiments. $\mathrm{CXB}$ treatment almost eliminated the enhancement of VM formation by $\mathrm{IR}$ in vitro and in vivo, partially due to COX-2 inhibition. Four potential off-targets were predicted by molecular docking. Among them, aminopeptidase N (APN) and integrin alpha-V (ITAV) were remarkably inhibited in protein expression and enzyme activity in vitro or in vivo, consistent with the remarkable reduction of VM formation in $\mathrm{H} 460$ xenografts in BALB/C mice. In conclusion, CXB dramatically blocked VM through inhibiting newly identified off-targets APN and ITAV, other than COX-2, then radiosensitizing NSCLC.

Keywords: celecoxib, vasculogenic mimicry, radiosensitizing effect, off-target effect, lung cancer, cyclooxygenase-2, aminopeptidase $\mathbf{N}$, integrin alpha-V 


\section{INTRODUCTION}

Celecoxib (CXB), a selective inhibitor of cyclooxygenase-2 (COX-2), has shown capability of radiosensitization in several cancer cell lines in experimental studies in the last decades (1-3). The above effects are not always associated with COX-2 enzyme inhibition. Dittmann et al. (4) found that the radiosensitization effect of CXB was independent of the inhibition of COX-2 but related to mediating nuclear epidermal growth factor receptor (EGFR) transport and DNA repair. Another study also reported that c-Myc could be considered an off-target of CXB in its beneficial effect on cancer treatment (5). Therefore, we speculate that there may exist other potential off-targets of $\mathrm{CXB}$ contributing to its radiosensitization effect.

Studies conducted by Brown claimed that vasculogenesis, a process of the formation of blood vessels from circulating cells, plays a crucial role in the resistance of solid tumors to radiotherapy $(6,7)$. Other studies supported this claim by presenting that angiogenesis involving endothelial cells (ECs) sprouting from nearby blood vessels contributed to radiotherapy resistance $(8,9)$. Recently, vasculogenic mimicry (VM) was revealed as a novel mechanism underlying vasculature development in tumors, with the ability to form fluid-conducting structures in an EC-free manner by tumor cells themselves $(10,11)$.

Lung cancer is the leading cause of cancer deaths among men and women (12). Non-small cell lung cancer (NSCLC) is the most common type of lung cancer and has a really high level of tumor metastasis (13). A large number of NSCLC patients receive radiotherapy during the entire course of cancer treatment. However, it is often of tumor relapse and distant metastasis due to radiation resistance $(14,15)$. VM has been observed in NSCLC tissues in some studies (16-18). VM constituted an important factor for tumor relapse and distant metastasis in glioblastoma, breast, and lung cancers (19-22). However, the role of VM in radiation resistance and relapse of NSCLC remains unclear.

Tumor neovascularization targeted drugs including Avastin, Endostar, sorafenib, sunitinib, anotinib, apatinib have been used as the antitumor clinical practice in many solid tumors, including NSCLC (23) and hepatocellular carcinoma (24). However, these drug resistance indicates that there are some compensation for angiogenesis, including VM (25). Thus, if a drug can effectively inhibit VM, it has the potential to remove anti-angiogenesis resistance and improve clinical outcomes.

Previous studies demonstrated that phosphatidylinositol 3kinase (PI3K) and vascular endothelial growth factor (VEGF), and COX-2 participated in VM formation (26-28). It was reported that inhibition of COX-2 by CXB led to impairment of VM formation in U87 cells and xenografts through downregulation of prostaglandin E2 and protein kinase C (28). Additionally, CXB was reported to destroy VM channels in brain glioma and breast cancer cells $(29,30)$. However, whether CXB exerts radiosensitization effects on NSCLC cells and xenografts via inhibiting VM formation and regulating off-targets needs to be elucidated.

In the current study, we investigated the effect of CXB on VM formation after irradiation (IR) treatment in lung cancer in vitro and in vivo. Furthermore, we explored the new off-targets of CXB in VM using molecular docking to clarify the mechanism by which CXB radiosensitizes NSCLC.

\section{MATERIALS AND METHODS}

\section{In Vitro Experiment and Irradiation Treatment}

Human-derived NSCLC cell lines (A549, H460, HCC78, etc.) and mouse-derived Lewis lung cancer (LLC) cells were purchased from the Cell Bank of Typical Culture Preservation Committee of Chinese Academy of Sciences (Shanghai, China). As a mouse brain capillary EC line, bEnd. 3 cell was used as a positive control of VM formation in this study (31). Cells were cultured in RPMI1640 culture medium (Gibco, USA) supplemented with $10 \%$ fetal bovine serum (HyClone, USA), $100 \mathrm{U} / \mathrm{ml}$ of penicillin, and $100 \mu \mathrm{g} / \mathrm{ml}$ of streptomycin at $37^{\circ} \mathrm{C}$ with $5 \% \mathrm{CO}_{2}$.

The influence of CXB at different doses $(0-80 \mu \mathrm{g} / \mathrm{ml})$ for $24 \mathrm{~h}$ or at a certain dose $(0,15$, and $30 \mu \mathrm{g} / \mathrm{ml})$ for $0-10$ days on the cellular viability of A549 cells was assessed by CCK-8 test (Beyotime Biotechnology, China) according to the manufacturer's instructions. The result of CCK- 8 was used to identify the suitable dose of CXB for the following study.

The cells were assigned into the control group, CXB group, IR group, and IR plus CXB group. The CXB group was incubated with CXB $(15 \mu \mathrm{g} / \mathrm{ml}$ from Sigma-Aldrich Corporation, Saint Louis, USA) for $24 \mathrm{~h}$; and the IR group was exposed to X-ray (XRAD 320, USA) at a dose of 5 Gy. The IR plus CXB group was treated with both CXB and X-ray. The control group was treated with $0.1 \%$ dimethyl sulfoxide (DMSO). IR was delivered at a dose rate of 2,058 cGy/min with $35-\mathrm{cm}$ height.

\section{In Vivo Experiment and Irradiation Treatment}

$\mathrm{BALB} / \mathrm{c}$ nude mice and C57 mice (aged 6-8 weeks) were supplied by Animal Laboratory Center of Daping Hospital (Chongqing, China). A total of $2 \times 10^{6}$ cells at passage 3 after cell recovery was resuspended in $100 \mu \mathrm{l}$ of physiological saline solution and subcutaneously injected into the right hind limb of BALB/c nude mice and C57 mice, to build xenograft models. After 7 to 10 days, the tumor tissue had grown to about $7 \mathrm{~mm}$ in diameter, and then $\mathrm{BALB} / \mathrm{c}$ nude mice and $\mathrm{C} 57$ mice were randomly assigned to the control, CXB, IR, and IR plus CXB groups ( $n=$ 6 each). $\mathrm{C} 57$ mice in the CXB group received CXB suspended in maize oil at a dose of $50 \mathrm{mg} / \mathrm{kg} \cdot \mathrm{bw}$ by gavage for 5 days. The above exposure dose was calculated based on AUC0-24 and equivalent to the clinical dose of about $200 \mathrm{mg}$ twice daily (32). $\mathrm{BALB} / \mathrm{c}$ mice in the CXB group were given CXB in drinking water at a dose of $15 \mu \mathrm{g} / \mathrm{ml}$ for 4 weeks. The IR group received 8 Gy of IR per day for 3 days continually for C57 mice and BALB/c nude mice. The IR plus CXB group received IR and CXB treatment simultaneously. The control group received maize oil by gavage or drinking water without CXB for $\mathrm{C} 57$ and $\mathrm{BALB} / \mathrm{c}$ mice. After being intraperitoneally injected with procaine for anesthesia and fixed with leg jig and put into the irradiator, mice were vertically irradiated with X-rays (X-RAD 320, USA) only in the field of the right hind limb. The IR was delivered at a dose rate 
of 4,518 cGy/min with $45-\mathrm{cm}$ height. Tumor tissues were collected when the mice displayed morbidity or the tumor was with ulcer. Survival experiment was also assessed using C57 mice with the same grouping described as above (five mice in each group). On the 50th day, all mice were sacrificed by cervical dislocation. All animal procedures were performed with the approval of the Laboratory Animal Welfare and Ethics Committee (SYXK-PLA-20120031) of Army Medical University (Chongqing, China).

\section{Assay of Vasculogenic Mimicry Channels In Vitro}

The three-dimensional culture of Matrigel (BD Biosciences Corporation, USA) was used to simulate the formation of VM channels of lung cancer in vitro. Briefly, the Matrigel low growth factor matrix was melted into liquid at $4^{\circ} \mathrm{C}$. Matrigel of $300 \mu \mathrm{l}$ was added per well in the pre-cooled 24 -well cell culture plate that was placed on ice. Then, the culture plate was placed at $37^{\circ} \mathrm{C}$ for $30 \mathrm{~min}$ to curdle the Matrigel. After solidification, A549, H460, HCC78, and bEnd.3 cells were seeded on the Matrigel. After incubating for $24 \mathrm{~h}$, cells were assigned into the control group, CXB group, IR group, and IR plus CXB group and received corresponding treatments, followed by incubation at $37^{\circ} \mathrm{C}$ for $7 \mathrm{~h}$. The effects of different treatments on the VM channels of lung cancer cells were observed with an inverted microscope (OMI 3000B, Leica, Germany).

\section{Cyclooxygenase-2 Expression in Tumor Tissues and Cells}

COX-2 expression in tumor tissues from $\mathrm{BALB} / \mathrm{c}$ nude mice was assayed by immunofluorescence staining. Rat anti-mouse COX-2 monoclonal antibody (Mcox-2, Abcam), and Alexa Fluor ${ }^{\circledR} 488$ rabbit anti-rat secondary antibody and Alexa Fluor ${ }^{\circledR} 593$ goat anti-rat secondary antibody (both from Abcam) were used. Nuclei were stained by 4'6-diamidino-2-phenylindole (DAPI). The experiments were carried out in triplicate. Images were acquired using a microscope (BX53, Olympus, Japan).

A549 and H460 cells were seeded in 24-well plates $\left(1.5 \times 10^{4}\right.$ cells/well) pre-placed with sterilized glass slides and were assigned into the four groups. After CXB and IR treatment, a monolayer of cells was fixed with $4 \%$ (vol/vol) paraformaldehyde at $37^{\circ} \mathrm{C}$ for 10 $\mathrm{min}$, followed by $10-\mathrm{min}$ incubation at room temperature with $0.2 \%$ (vol/vol) Triton X-100. After being washed with phosphatebuffered saline (PBS), non-specific binding was blocked with $10 \%$ fetal bovine serum (FBS) in PBS. Anti-COX-2 rabbit polyclonal antibodies (1:50; Cell Signaling Technology) diluted in PBS were added at $4^{\circ} \mathrm{C}$ and incubated overnight, avoiding light; and then after being washed with PBS, the slides were incubated with DyLight ${ }^{\circledR}$ 594 conjugated secondary antibody (Thermo Fisher, USA) in PBS for $1 \mathrm{~h}$ at room temperature. Finally, the slides were mounted in $0.1 \%$ (wt/vol) DAPI (1:50; Invitrogen) for nuclear counterstaining for $5 \mathrm{~min}$ at room temperature and observed under a Leica OMI 3000B fluorescence microscope (Leica, Germany).

COX-2 protein expressions in cells were tested by Western blotting, using the primary and secondary antibodies from Abcam (USA).

\section{Celecoxib Relocation and Cyclooxygenase-2-Independent Target Screening}

The first step was identification of receptor protein database. Based on Qiagen's gene pool involved in neovascularization, we selected 84 genes from an angiogenesis PCR chip, including genes for growth factors and their receptors, chemokines, cytokines, cell substrates, adhesion molecules, proteases and their inhibitors, and transcription factors. The proteins expressed by these genes constituted a database of potential receptor proteins.

The second step was structure screening and structural pretreatment for potential receptor proteins. The 3D structure of each protein was retrieved in the Protein Data Bank (PDB) database and then screened. The screening criteria were as follows: first, proteins without experimental crystal structure data or with NMR structure data only were excluded; second, proteins that only reported the structure of the complex formed by the protein and small molecules were excluded. For each of the remaining candidate proteins, the most desirable structure was selected after comprehensively considering its crystal structure resolution, fragment length, functional regions, and active sites. The MGLTools 1.5.6 was used to treat the receptor protein structure, including adding polar hydrogen atoms, removing non-polar hydrogen atoms, and storing the file in.pdbqt format. The structural data of $\mathrm{CXB}$ were downloaded from the PubChem database and processed into.pdbqt format using MGLTools.

The third step was determination of molecular docking box. In the case of docking a small ligand molecule with a series of receptor proteins, a docking box (i.e., an energy grid of the atom probe) was placed centering on the entire protein structure. For example, the center of the AKT1 protein (PDB ID: 4EJN) was $32.054 \times 41.233 \times 13.569$, and a rectangular box having a side length of $40 \times 50 \times 60$ was set, so that the box contained the entire protein molecule. The docking distance of the docking box for all proteins was set to $1.0 \mathrm{~A}$.

The final step was docking calculation. A semi-flexible docking method was used to treat protein receptors as rigid materials, while small molecule ligand conformations could vary. AutoDock Vina 1.1.2 was used as a molecular docking tool to determine the binding sites and affinities of $\mathrm{CXB}$ to protein receptors.

\section{Western Blotting}

After being harvested, cells were lysed in radioimmunoprecipitation assay (RIPA) lysis and extraction buffer (Beyotime Biotechnology, China) at $4^{\circ} \mathrm{C}$ with protease inhibitors and phosphatase inhibitors (Beyotime Biotechnology, China). Protein concentrations were detected using a bicinchoninic acid protein assay kit (Beyotime Biotechnology, China). Samples containing the same amount of protein were separated using $8 \%-10 \%$ sodium dodecyl sulfatepolyacrylamide gel electrophoresis (SDS-PAGE) electrophoresis and then electrotransferred onto polyvinylidene fluoride membranes (Bio-Rad Laboratories, USA), followed by blocking with the blocking buffer (Beyotime Biotechnology, China). These 
membranes were incubated at $4^{\circ} \mathrm{C}$ overnight with the primary antibodies (Abcam, USA) and then incubated with the secondary antibodies (Abcam, USA). Signals of the protein bands were detected using an enhanced chemiluminescence system (Millipore, Billerica, MA, USA). Target proteins were visualized with the FluorChem HD2 system (ProteinSimple, USA).

\section{Aminopeptidase N Enzyme Activity Assay}

Aminopeptidase N (APN) enzyme activity was measured by spectrophoto-metrically method using L-leucine- $p$-nitroanilide (Sigma-Aldrich Corporation, Saint Louis, USA) as an APN substrate. Whole-cell (A549 and H460) suspensions were prepared in test tubes and then washed with PBS. Thereafter, $5 \times 10^{5}$ cells were resuspended in $200 \mu$ of PBS in each well of a 96-well microplate, and the substrate was added at a final concentration of $1.6 \mathrm{mM}$. APN enzyme activity was estimated by measuring the absorbance at $405 \mathrm{~nm}$ using a microplate reader (LabSystems, Multiskan Bichromatic) every $15 \mathrm{~min}$ during incubation at $37^{\circ} \mathrm{C}$.

\section{Lentivirus Transfection}

Tumor cells were transfected with lentivirus to inhibit integrin alpha-V (ITAV) expression. On the first day, A549 and H460 cells were seeded into 12 -well plates $\left(4 \times 10^{4}\right.$ cells/well $)$ and incubated for $24 \mathrm{~h}$. On day 2, $1 \mu \mathrm{l}$ of configured empty or ITAV vector virus transfection solution was added into the culture media per well and then incubated for $24 \mathrm{~h}$. Transfection effect was observed under a fluorescence microscope on days 3-5. On day 6, well-transfected cells were selected and seeded into sixwell plates to be incubated for $72 \mathrm{~h}$. Cells that grew well were seeded into a $25-\mathrm{cm}^{2}$ flask and subcultured. The lentivirustransfected cells were seeded into a 3D-Matrigel-coated 96-well plate to observe VM formation. Images were acquired using a microscope (OMI 3000B, Leica, Germany).

\section{Vasculogenic Mimicry Formation Identification In Vivo}

$\mathrm{VM}$ formation in cells was also assessed using periodic acid solution (PAS) method as previously described (33). In brief, tumor sections were incubated with $0.5 \%$ PAS for $10 \mathrm{~min}$. After being rinsed with distilled water for 2-3 $\mathrm{min}$, tumor sections were incubated with Schiff solution for 15-30 min in a dark chamber and rinsed again. Tumor sections were finally counterstained with hematoxylin. PAS staining showed that the vessel-like structure was composed of tumor cells and basal membrane (VM formation). Images were acquired using a microscope (BX53, Olympus, Japan).

\section{Vasculogenic Mimicry Formation Identification In Vivo by Immunofluorescence Staining}

$\mathrm{VM}$ formation identification in vivo was also observed by immunofluorescence staining using rat anti-mouse CD31 monoclonal antibody (mCD31, Santa Cruz), Alexa Fluor ${ }^{\circledR}$ 488 rabbit anti-rat secondary antibody and rabbit anti-human Ecadherin monoclonal antibody (hE-cad, Abcam), and Alexa Fluor ${ }^{\circledR}$ 593 goat anti-rabbit secondary antibody (Abcam). The expression of mCD31 was taken as the average immunofluorescence density and analyzed using Image J software (Softonic International, Spain). The images were analyzed with Image-Pro Plus (IPP) software (Media Cybernetics, USA). VM channels were identified as hE-cadpositive (in red) and mCD3-negativel (in green) channels. Images were acquired using a microscope (Olympus, BX53, Japan).

\section{Immunohistochemistry}

The lung cancer tissues from C57 mice were prepared for paraffin tissue slices. The slices were baked at $60^{\circ} \mathrm{C}$ in an oven for $2 \mathrm{~h}$ followed by deparaffinization and then were repaired with antigen retrieval solution (Tris-EDTA buffer, $\mathrm{pH}$ 9.0). These slices were incubated with endogenous peroxidase blocking solution and then blocked with goat serum. Next, these slices were incubated with rabbit monoclonal antibody anti-ITAV (EPR 16800, dilution 1:500, Abcam, USA), rabbit monoclonal antibody anti-COX-2 (EPR12012, dilution 1:1,000, Abcam, USA), and rabbit monoclonal antibody anti-CD13 (EPR4058, dilution 1:1,200, Abcam, USA) overnight at $4^{\circ} \mathrm{C}$. Thereafter, these slices were incubated with secondary antibody (MaiXin, China) followed by incubating with DAB color reagent (MaiXin, China). Finally, the slices were stained with hematoxylin somatic cell staining solution (MaiXin, China) and then air-dried and mounted. They were observed using a fluorescence microscope (Olympus, Japan). The images were analyzed with IPP software (Media Cybernetics, USA). Images were acquired using a microscope (Olympus, BX53, Japan).

\section{Statistical Analysis}

The significance of difference among groups was determined by ANOVA test, and the difference between two groups was determined by SNK assay using IBM SPSS 21.0 (USA). The significance of difference in the average fluorescence intensity of COX-2 in cells between control and CXB groups was determined by $t$-test. The survival analysis was assessed by Kaplan-Meier method. $p$-Values $<0.05$ were considered statistically significant.

\section{RESULTS}

\section{Celecoxib Exerted Radiosensitizing Effect in Lung Cancer Xenografts}

Compared with that in the control group, the tumor growth was significantly inhibited in IR plus CXB group in both BALB/c mice implanted with $\mathrm{H} 460$ cells and C57 mice implanted with LLC cells $(p<0.05$; Figures 1A, B). In addition, CXB combined with IR remarkably prolonged the survival duration of mice with xenografts $(p=0.013$; Figure 1C).

\section{Celecoxib Exerted Radiosensitizing Effect via Inhibiting Vasculogenic Mimicry Formation}

In vitro tube-forming experiments showed that A549, H460, and HCC78 cells had an ability to form vessel-like structures with VM characteristics in 3D Matrigel (Figure 2A). To determine the concentration of CXB treatment, CCK-8 assays were performed. We found that $15 \mu \mathrm{g} / \mathrm{ml}$ of CXB incubation did not dramatically inhibit the growth of A549 cells for $24 \mathrm{~h}$ (Figure 2B) or for 
A BALB/c nude mice

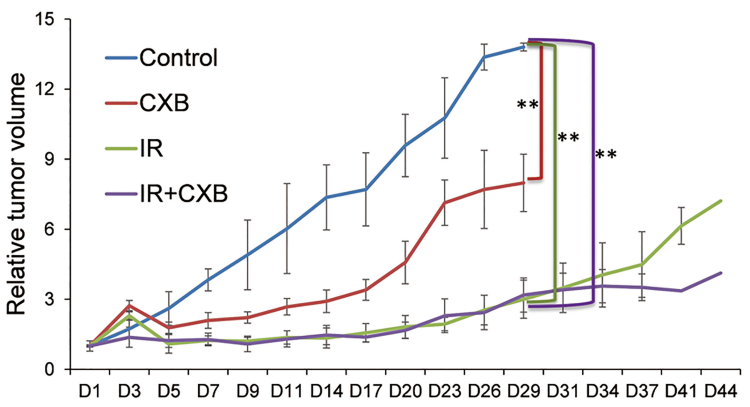

в $\quad$ 557 mice

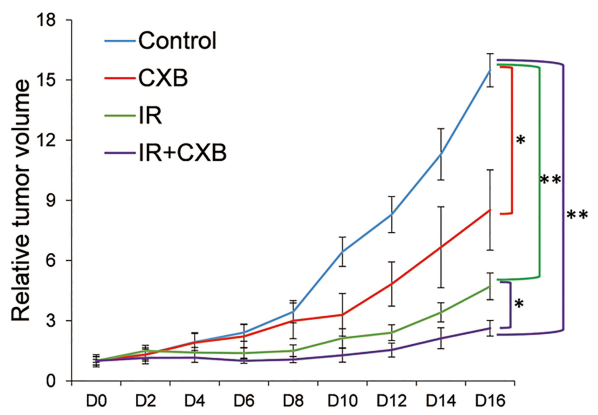

c Kaplan-Meier survival analysis

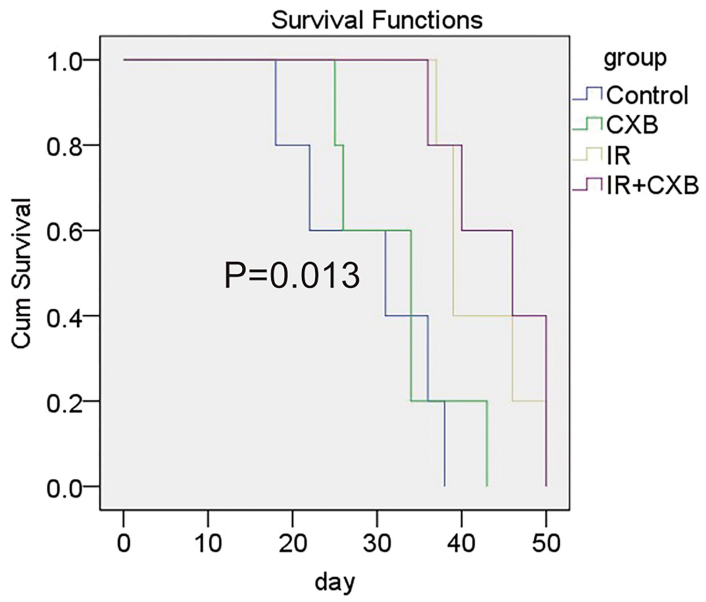

FIGURE 1 | CXB had radiosensitizing effect. BALB/c nude mice and C57 mice were randomly assigned to the control, $\mathrm{CXB}, \mathrm{IR}$, and IR plus $\mathrm{CXB}$ groups. (A) The tumor growth curve of BALB/c nude mice injected with $\mathrm{H} 460$ cells ( $n=6$, each group). Compared with that in the control group, the tumor growth was significantly inhibited in IR plus CXB group in xenografts. Comparison with the control group: ${ }^{*} p<0.05$ and ${ }^{* *} p<0.01$. (B) Tumor formation experiments in C57 mice bearing LLC xenografts $(n=6$, each group). Data are expressed as the mean $\pm \mathrm{SD}$. The tumor growth was significantly inhibited in IR plus CXB group in xenografts. Comparison with the control group: ${ }^{*} p<0.05$ and ${ }^{* *} p<0.01$. (C) Survival analysis of C57 mice bearing LLC xenografts, $p=0.013$ among groups. CXB, celecoxib; IR, irradiation; LLC, Lewis lung cancer.
10 days (Figure $2 \mathrm{C}$ ). Thus, we chose $15 \mu \mathrm{g} / \mathrm{ml}$ as the treatment concentration of CXB for the following experiments. Meanwhile, IR treatment (5 Gy) significantly enhanced the ability of VM formation in all the three cell lines compared with the control group (data not shown). However, CXB treatment eliminated the formation of VM in A549 cells, whether with or without IR treatment (Figures 2D, E).

\section{Celecoxib Inhibited the Expression of Cyclooxygenase-2 in Cells and Xenografts}

As shown in Figures 3A, B, COX-2 expression levels in A549 and $\mathrm{H} 460$ cells were significantly decreased by CXB. The COX-2 protein expression in A549 cells significantly decreased after CXB treatment, while IR treatment resulted in a remarkable increase in COX-2 expression (Figures 3C, D). Additionally, a combination treatment of IR and CXB suppressed the increment of COX-2 protein expression induced by IR (Figures 3C, D). In immunofluorescence staining assay, COX-2 expression was enhanced by IR treatment in H460 xenografts and noticeably reduced but not eliminated by $\mathrm{CXB}$ treatment with or without the combination of IR treatment (Figures 3E, F).

However, compared with the almost eliminatory effect on VM formation caused by $\mathrm{CXB}$ alone or combination with IR treatment, the reduction degrees in COX-2 protein expression and COX-2 immunofluorescence density in IR group were likely lower. These results suggest that $\mathrm{CXB}$ may perform an eliminatory effect on the formation of VM and enhance radiosensitivity not only via inhibiting COX-2 but also through interacting with other potential novel targets.

\section{Four Proteins (Aminopeptidase N, Integrin Alpha-V, AKT1, and NOS3) Were Screened as Potential Off-Targets of Celecoxib}

Of the 84 proteins involved in neovascularization, 54 had identified 3D structure. According to molecular docking, 21 proteins showed relatively high affinity with $\mathrm{CXB}$, of which 14 had free binding energy of less than $-8.0 \mathrm{kcal} / \mathrm{mol}$ and seven had less than $-9.0 \mathrm{kcal} /$ mol, particularly one with the lowest free binding energy of -10.6 $\mathrm{kcal} / \mathrm{mol}$ (Table 1). Since free binding energy lower than $-9.0 \mathrm{kcal} /$ mol was considered of high affinity, we selected the seven proteins for further validation. To determine whether CXB could bind to the functional domain of the seven proteins, we compared the binding site and energy between $\mathrm{CXB}$ and reported inhibitor of each protein, MK-2206 or AZD5363 for AKT1, bestatin for APN, endostatin or rapamycin for ITAV, and L-NAME or L-NIO for NOS3. Comparative molecular docking revealed that $\mathrm{CXB}$ could bind to the functional domain of four proteins, APN, ITAV, AKT1, and NOS3 (Figure 4), among which APN showed the highest affinity.

\section{Aminopeptidase $\mathbf{N}$ and Integrin Alpha-V Were Identified as Off-Targets In Vitro}

Cellular protein extraction from A549 cells was used for Western blotting analyses. Western blotting showed that IR at a dose of 5 Gy significantly increased ITAV and APN levels, while CXB treatment at a concentration of $15 \mu \mathrm{g} / \mathrm{ml}$ significantly decreased ITAV and APN levels (Figure 5A). Furthermore, IR plus CXB 
A
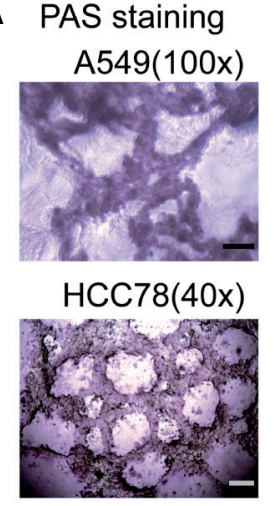

D

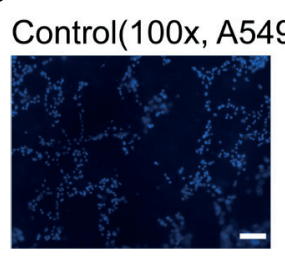

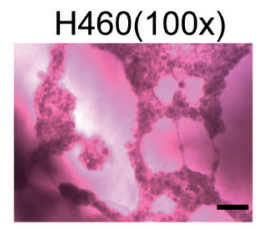

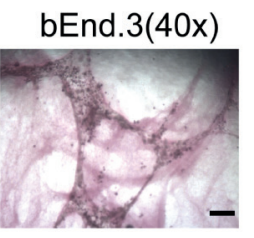

$\mathrm{CXB}(100 \mathrm{x}, \mathrm{A} 549)$

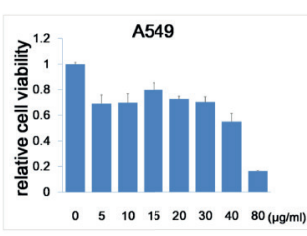

E

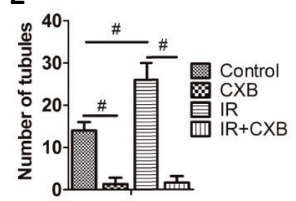

C

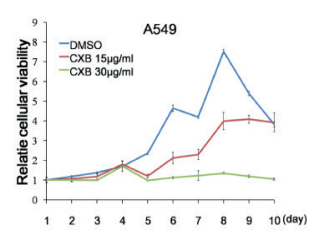

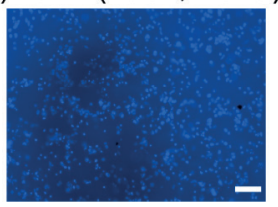

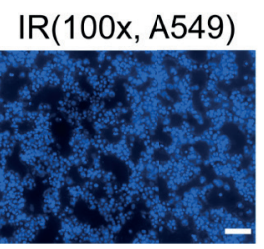

$\mathrm{IR}+\mathrm{CXB}(100 x, \mathrm{A549})$

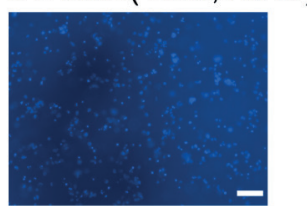

FIGURE 2 | CXB exerted radiosensitizing effect via inhibiting VM formation. (A) VM formation in A549, H460, HCC78, and bEnd.3 cells grown on the 3D Matrigel in representative images with PAS staining. Scale bar, $500 \mu \mathrm{m}$. (B) The influence of CXB at different doses treated for $24 \mathrm{~h}$ on A549 cells analyzed by CCK-8 assay. CXB at a dose of $15 \mu \mathrm{g} / \mathrm{ml}$ did not dramatically inhibit the growth of A549 cells. (C) The influence of DMSO, and $15 \mathrm{and} 30 \mu \mathrm{g} / \mathrm{ml}$ of CXB treatment for different durations on A549 cells analyzed by CCK-8 assay. CXB treatment at a dose of $15 \mu \mathrm{g} / \mathrm{ml}$ for 10 days did not dramatically inhibit the growth of A549 cells.

(D) Pictures of tubules in different groups in A549 cells. (E) The number of tubules in different groups (the control, CXB, IR, and IR plus CXB groups) in A549 cells. Data are expressed as the mean \pm SEM $(n=3) .{ }^{*} p<0.001$. Scale bar, $500 \mu \mathrm{m}$. CXB, celecoxib; VM, vasculogenic mimicry; PAS, periodic acid solution; DMSO,

dimethyl sulfoxide; IR, irradiation.

treatment remarkably reduced the increment of ITAV and APN levels induced by IR (Figure 5A). However, the protein expression of AKT1, p-AKT, and NOS3 showed no significant difference between these treatments. Thus, APN and ITAV were more likely to be the potential off-targets of CXB.

Furthermore, APN enzyme activity experiment in cells (A549 and $\mathrm{H} 460$ ) showed that, compared with the control group, IR at a dose of 5 Gy significantly increased APN enzyme activity by about $25 \%$, while CXB reduced APN enzyme activity by about $20 \%$ (Figure 5B). Importantly, a combination of IR with CXB treatment significantly resulted to approximately $37 \%$ reduction in APN enzyme activity as compared with the IR alone group ( $p=$ 0.030 and 0.010 for A549 and H460 cells, respectively; Figure 5B).

Inhibition of ITAV expression in cells (A549 and H460) by lentivirus transfection remarkably suppressed VM formation (Figures 5C, D). This result confirmed that the suppression of ITAV expression by CXB could effectively repress the formation of VM.

\section{Celecoxib Inhibited Irradiation-Enhanced Vasculogenic Mimicry Formation in Xenografts}

PAS staining showed more vessel-like structures in $\mathrm{H} 460$ xenografts of $\mathrm{BALB} / \mathrm{c}$ mice in IR group than in the control group, while a combination of IR treatment with $\mathrm{CXB}$ noticeably inhibited this enhancement (Figures 6A, B). In A549 xenografts in BALB/c nude mice, immunofluorescence staining also showed that the formation of VM significantly increased after IR treatment, while a combination treatment of IR and CXB eliminated such increment (Figures 6C, D). The above results suggest that CXB can effectively block the formation of VM in vitro and in vivo, which may enhance the sensitivity of lung cancer cells and tissues to IR, supported by the remarkable different changes in tumor volume between the IR group and IR plus CXB group.

\section{Confirmation of Novel Targets of Celecoxib in Tumor Tissue}

To verify the off-target effect of CXB in different animal models, the protein expression of COX-2, ITAV, and APN was confirmed in LLC xenografts. The LLC xenografts in C57 mice in the IR group showed higher COX-2, ITAV, and APN levels than those in the control group (Figures 7A, B), while $15 \mu \mathrm{g} / \mathrm{ml}$ of CXB treatment remarkably decreased these protein expression levels. Furthermore, these increments of COX-2, APN, and ITAV levels caused by IR were eliminated by CXB treatment (Figures 7A, B).

\section{DISCUSSION}

To date, IR as a treatment of NSCLC still confronted tumor relapse due to radiation resistance. In the present study, we 

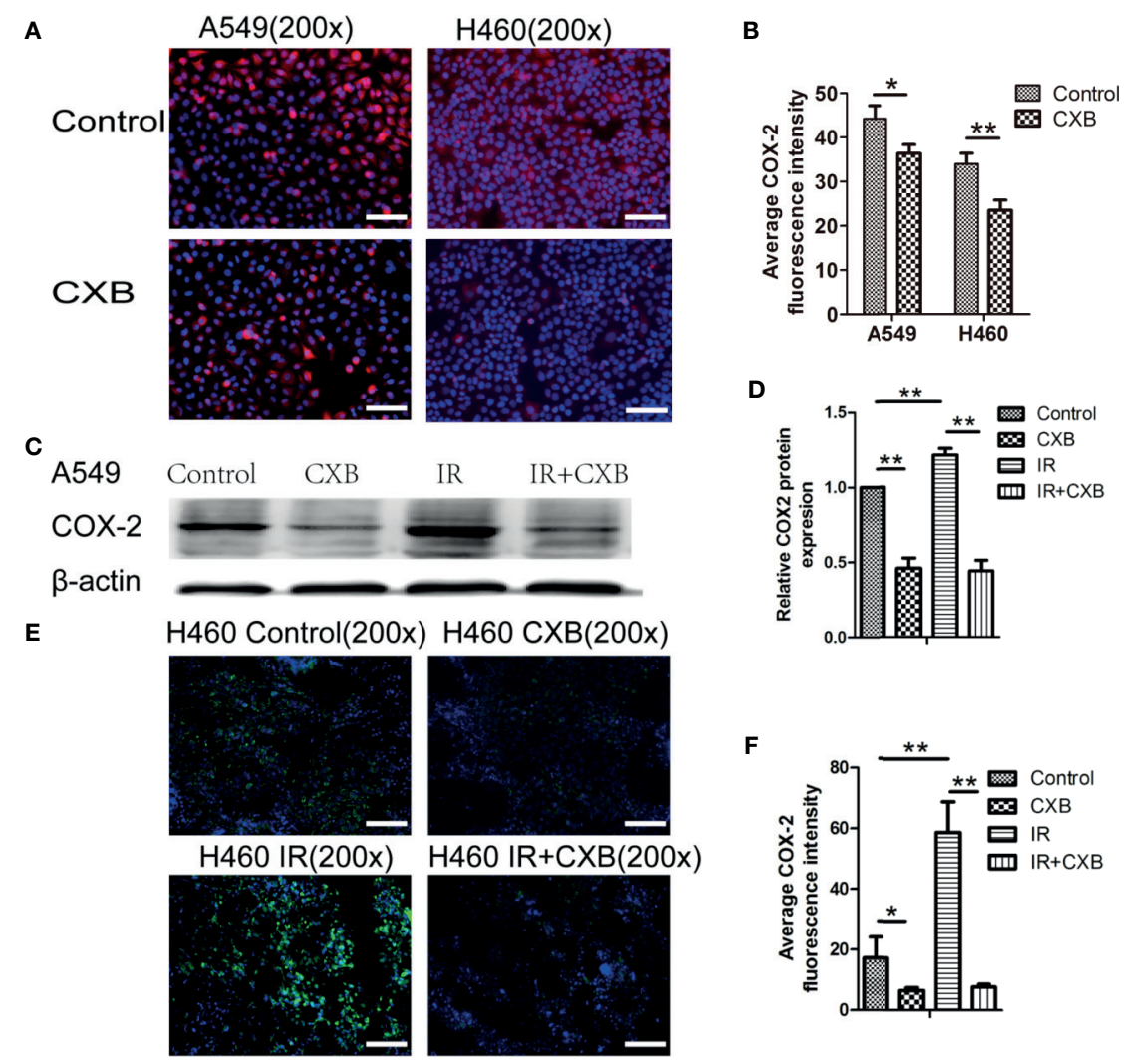

FIGURE 3 | The expression of COX-2 in cells and the influence of CXB and/or IR on the expression of COX-2. (A) COX-2 immunofluorescence staining in A549 and H460 cells (blue, nucleus; red, COX-2). Scale bar, $100 \mu \mathrm{m}$. (B) Average fluorescence intensity of COX-2 in cells. Error bars indicate standard division. COX-2 expression levels in A549 and H460 cells were significantly decreased by CXB. ${ }^{\star} p<0.05,{ }^{\star \star} p<0.01$. (C) COX-2 protein expression in A549 cells analyzed by Western blotting (picture was cropped). (D) The relative COX-2 protein expression in A549 cells. ${ }^{* *} p<0.01$. (E) COX-2 immunofluorescence staining in tumor tissues from BALB/c nude mice (H460, $n=6$; blue, nucleus; red, COX-2). Scale bar, $100 \mu \mathrm{m}$. (F) Average fluorescence intensity of COX-2 in tumor tissues from BALB/c nude mice $(\mathrm{H} 460, n=6)$. Error bars indicate standard division. ${ }^{*} p<0.05$, ${ }^{* *} p<0.01$. COX-2, cyclooxygenase-2; CXB, celecoxib; IR, irradiation.

TABLE 1 | Molecular docking with free energy $-9.0 \mathrm{kcal} / \mathrm{mol}$ and below as the high affinity standard screened out seven optimal binding proteins.

\begin{tabular}{lcc}
\hline Receptor protein & PDB ID & Free binding energy (kcal/mol) \\
\hline APN & $4 F Y R$ & -10.6 \\
AKT1 & $4 E J N$ & -9.6 \\
NOS3 & $4 D 10$ & -9.6 \\
SPHK1 & $4 V 24$ & -9.4 \\
TGFA & $3 E 50$ & -9.3 \\
EPHB4 & $3 Z E W$ & -9.3 \\
ITAV & 1JV2 & -9.2 \\
\hline
\end{tabular}

APN, aminopeptidase N; AKT1, RAC-alpha serine/threonine-protein kinase; NOS3, nitric oxide synthase, endothelial; SPHK1, sphingosine kinase 1; TGFA, protransforming growth factor alpha; EPHB4, ephrin type $B$ receptor 4; ITAV, integrin alpha-V; PDB, Protein Data Bank.

found that IR enhanced VM in vitro and in vivo. Formation of VM channels is one of the most common causes of distant metastasis and poor prognosis in lung cancer $(21,22)$. Therefore, inhibiting VM channels is an important way to prevent tumor relapse and to improve clinical prognosis. Recently, several studies reported that mixed usage of chemicals and micelles exhibited destructive effects on VM channels in NSCLC, such as dequalinium modified paclitaxel plus ligustrazine micelles and paclitaxel plus honokiol micelles $(34,35)$. Another method to destroy VM formation in NSCLC is using liposomes (36). Since IR enhances VM in vitro and in vivo, we presume that VM is also an important factor for tumor recurrence after radiation.

One important finding in the present study was that CXB effectively eliminated VM formation in A549 and H460 cells and in murine tumor tissues; furthermore, CXB combined with IR prolonged the survival duration of mice with xenografts, consistent with its inhibitory effect on the formation of VM channels. In this study, we found that $\mathrm{CXB}$ as a single medicine could totally inhibit VM channel construction in NSCLC, thus contributing to its positive effect on radiosensitivity. $\mathrm{CXB}$ is known to play roles in suppressing inflammation, tumor growth, and angiogenesis and enhancing radiosensitivity and chemotherapy (37-39). Our findings also suggest that CXB can be used in an exciting novel disease treatment, i.e., as anti-cancer 

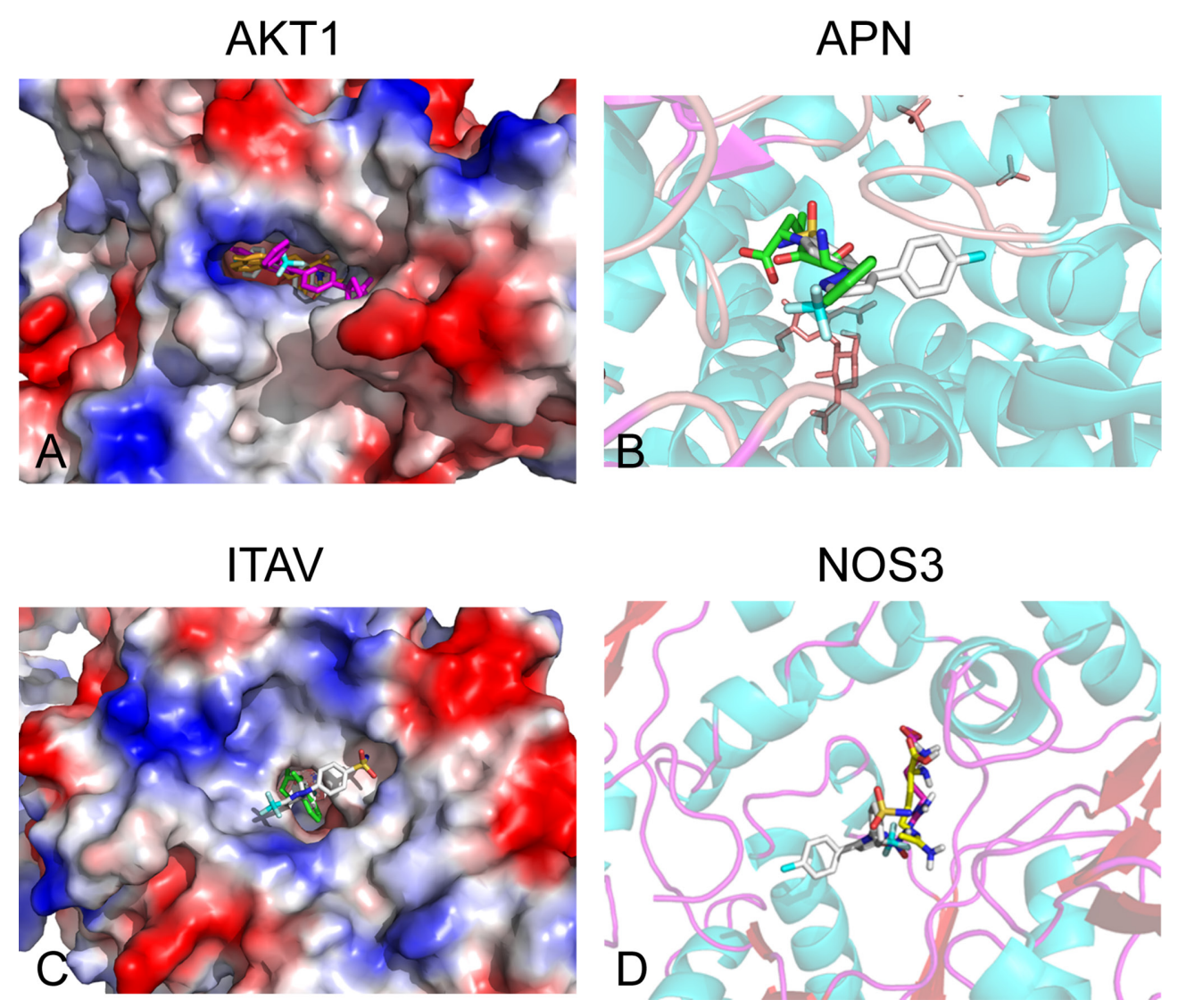

FIGURE 4 | Off-targets screening for CXB by molecular docking. Four proteins (APN, ITAV, AKT1, and NOS3) were screened as potential off-targets of CXB. (A) AKT1 was aligned with CXB and MK-2206 and AZD5363 docking structures. Rose red, MK-2206; yellow, AZD5363; white, CXB. (B) APN was compared with CXB and bestatin (BST) docking structures. Translucent, APN; green, BST; white, CXB. (C) ITAV was aligned with CXB and endostatin and rapamycin docking structures. Green, endostatin; brown, rapamycin; white, CXB. (D) NOS3 was aligned with CXB and L-NAME and L-NIO docking structures. The translucent molecule is NOS3 (4D1O); rose, L-NAME; yellow, L-NIO; and white, CXB. CXB, celecoxib; APN, aminopeptidase N; ITAV, integrin alpha-V.

therapy or radiosensitivity promoter, apart from its traditional usage in the treatment of rheumatoid arthritis and osteoarthritis for many years.

It is well known that VM is not the only factor that affects tumor growth. The tumor vasculature is complex in vivo, in which re-vascularization and alternative mechanisms for revascularization might be taking place. So although CXB significantly inhibited the formation of VM in Figure 2E, CXB plus IR in vivo only shrunk the size of the tumor instead of banishing it as shown in Figures 1A, B. These findings suggested that CXB improved the antitumor effect of IR, benefited the prognosis, or reduced IR resistance in vivo. Evidence from other studies showed that $\mathrm{CXB}$-erlotinib combination or CXB alone treatment can enhance radiosensitivity in A549 lung cells (40) and may be beneficial for patients with advanced NSCLC and EGFR wild type only (41). Apart from being used as a treatment of rheumatoid arthritis and osteoarthritis, CXB may hold promise of an antitumor treatment that requires further confirmation by clinical trials in the future.
As for VM identification, however, it was reported that PAS staining was not specific, and there is a lack of specific markers for VM and functional verification of tubular (10). In this study, we used not only PAS staining but also double staining in immunofluorescence. Mouse antibody mCD31 staining represents mouse-derived ECs (green); and hE-cad, a cell-cell adhesion molecule, staining represents human tumor-derived basal membrane (red) in Figure 6. Thus, we can identify the VM accurately. It is a novel method for VM verification in future research.

Moreover, another interesting and important finding in the present study was that CXB could inhibit not only the expression of COX-2 but also off-targets. In recent years, accumulating evidence has shown that CXB can exert anticancer effects, including promoting apoptosis, blocking cell cycles, and inhibiting angiogenesis, not relying on the COX-2 enzyme (42, 43), which means "off-target effect" of CXB. Molecular docking found that $\mathrm{CXB}$ could bind to the functional pocket of APN, NOS3, AKT1, and ITAV. Among these proteins, ITAV and APN 
A
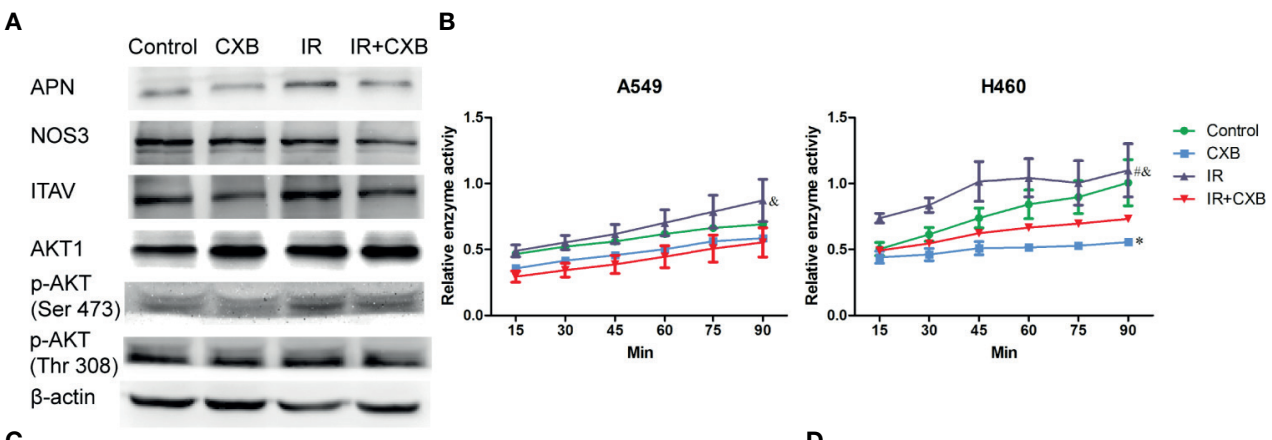

C

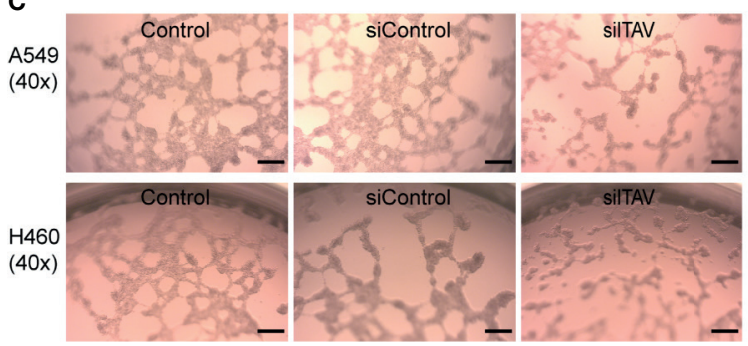

D

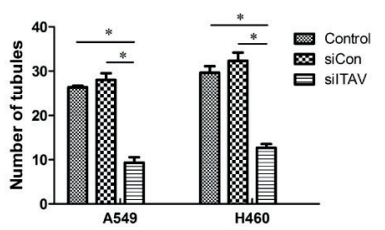

FIGURE 5 | Confirmation of off-targets of CXB in cells. (A) Protein expression levels assessed by Western blotting (picture was cropped). Western blotting showed that IR significantly increased ITAV and APN levels, while CXB treatment significantly decreased ITAV and APN levels. Furthermore, IR plus CXB treatment remarkably reduced the increment of ITAV and APN levels induced by IR. (B) Enzyme activity test. APN enzyme activity experiment in cells (A549 and H460).

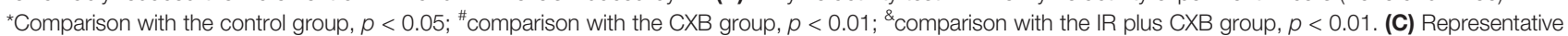
images of VM formation in A549 and H460 cells transfected with non-silencing siRNA (siCon) or siRNA-ITAV (silTAV), grown on the 3D Matrigel. Scale bar, $200 \mu \mathrm{m}$. (D) Number of tubules. Values are expressed as mean \pm SEM from three independent experiments. Inhibition of ITAV expression in cells (A549 and H460) by lentivirus transfection remarkably suppressed VM formation. ${ }^{*} p<0.05$. CXB, celecoxib; IR, irradiation; ITAV, integrin alpha-V; APN, aminopeptidase N; VM, vasculogenic mimicry.

had higher affinity with CXB; and the binding of CXB to ITAV and APN resulted in downregulation of these two proteins. The proteins APN and ITAV play important roles in tumor metastasis and angiogenesis (44-47). APN, also known as $\mathrm{CD13}$, has been reported to be related to poor prognosis when expressed in tumor tissues $(48,49)$. Recently, ITAV level in cancer tissue has been found positively correlated with tumor invasion and metastasis, such as in prostate cancer and osteosarcoma $(50,51)$. Thus, these proteins involved in tumor metastasis may have a strong relationship with VM, or participate in VM formation. Unfortunately, seldom studies reported the roles of these proteins in the formation of VM. One cellular study revealed that EGFR-integrin $\alpha v \beta 3$ complex impairment repressed VM in triple-negative breast cancer (52).

In the current study, vessel-like structures were formed in A549 and H460 cells with higher APN expression, suggesting that APN may participate in VM formation. Consistent with the effect of IR and CXB on VM formation, IR significantly increased APN levels in cells and mice, while CXB outstandingly decreased APN levels. Furthermore, CXB inhibited the increment of APN enzyme activity in cells. These findings indicated that CXB can be an inhibitor of APN and may be used for lung cancer treatment in clinical practice like other aminopeptidase inhibitors such as bestatin (53). Recently, one clinical study including 270 patients with NSCLC revealed that vascular
CD13 protein expression was correlated with poor overall survival in stage III and pN2+ NSCLC patients (54). To our best knowledge, no study has reported that aminopeptidase and its inhibitors play a role in VM formation. The present study provides moderate evidence that APN is involved in the formation of VM.

ITAV was another potential off-target of CXB in VM formation, as demonstrated by the current study. ITAV is one member of a family of cell adhesion proteins. Similar to the results of APN, IR significantly increased ITAV levels in A549 and $\mathrm{H} 460$ cells and in mice, while CXB remarkably decreased ITAV protein levels. Additionally, the increments of ITAV levels caused by IR in the tumor tissues of C57 mice were eliminated by CXB treatment. Furthermore, inhibition of ITAV expression by $\mathrm{CXB}$ and transfection of lentivirus into tumor cells induced a notable reduction of VM formation. These results identified a positive important role of ITAV in VM formation, which is a novel finding in lung cancer. Inhibition of ITAV by intetumumab, an anti-ITAV monoclonal antibody, has shown anti-migratory and anti-proliferative effects in vitro and therapeutic and preventive effects in vivo (55-58).

To our best knowledge, this is the first study to report that CXB could inhibit VM in radiosensitizing lung cancer. It is also the first study demonstrating that CXB has off-targets in the process of destroying VM. There were some limitations in this study. 


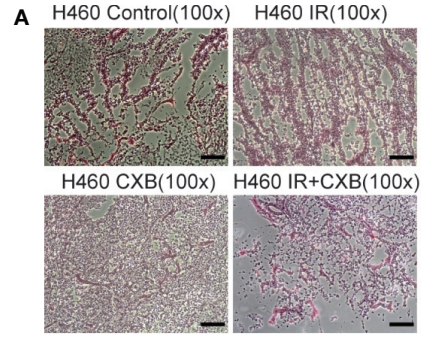

B

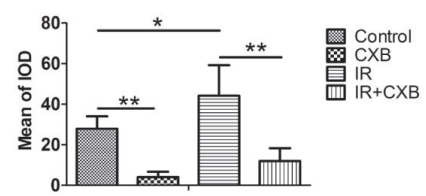

D

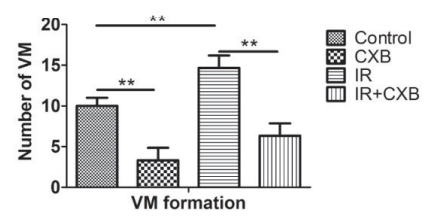

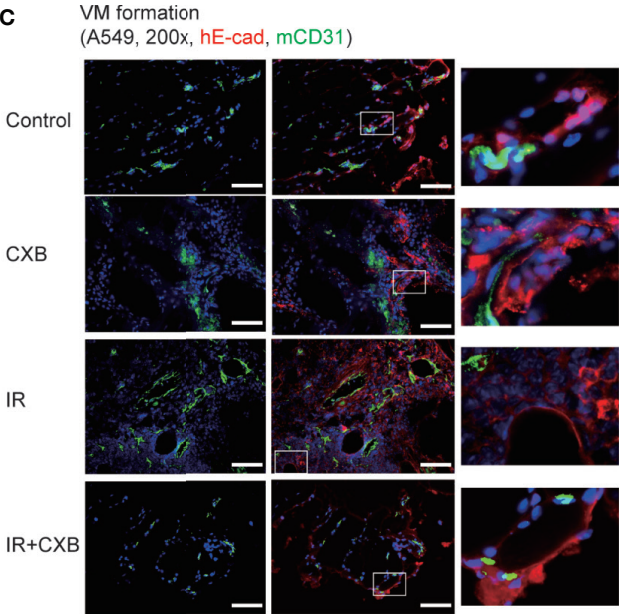

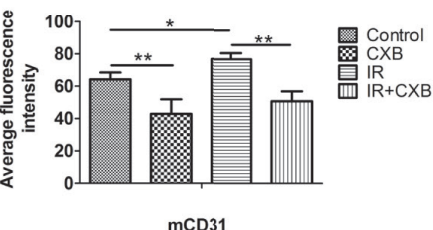

FIGURE 6 | VM change in BALB/c xenografts detected by PAS (H460) and immunofluorescence staining (A549). (A) PAS staining (H460): vessel-like structures were composed of tumor cells and basal membrane (VM formation). VM channels were identified as vessel-like structures composed of tumor cells and were PASpositive (red). Scale bar, $500 \mu \mathrm{m}$. (B) The mean of IOD test by PAS staining in tumor tissues. ${ }^{\star} p<0.05$, ${ }^{\star \star} p<0.01$. (C) Immunofluorescence staining of A549 cells (in A549 xenografts in BALB/c nude mice). mCD31 staining represents mouse-derived endothelial cells (green); hE-cad, a cell-cell adhesion molecule staining represents human tumor-derived basal membrane (red), and DAPI represents the cell nucleus (blue). VM channels were identified as mCD31-/hE-cad+. Scale bar, $100 \mu \mathrm{m}$. (D) The number of VM channels (left) and the expression of mCD31 (right) assessed by immunofluorescence staining in tumor tissues. ${ }^{\star} p<0.05$, ${ }^{* *} p<0.01$. VM, vasculogenic mimicry; PAS, periodic acid solution.
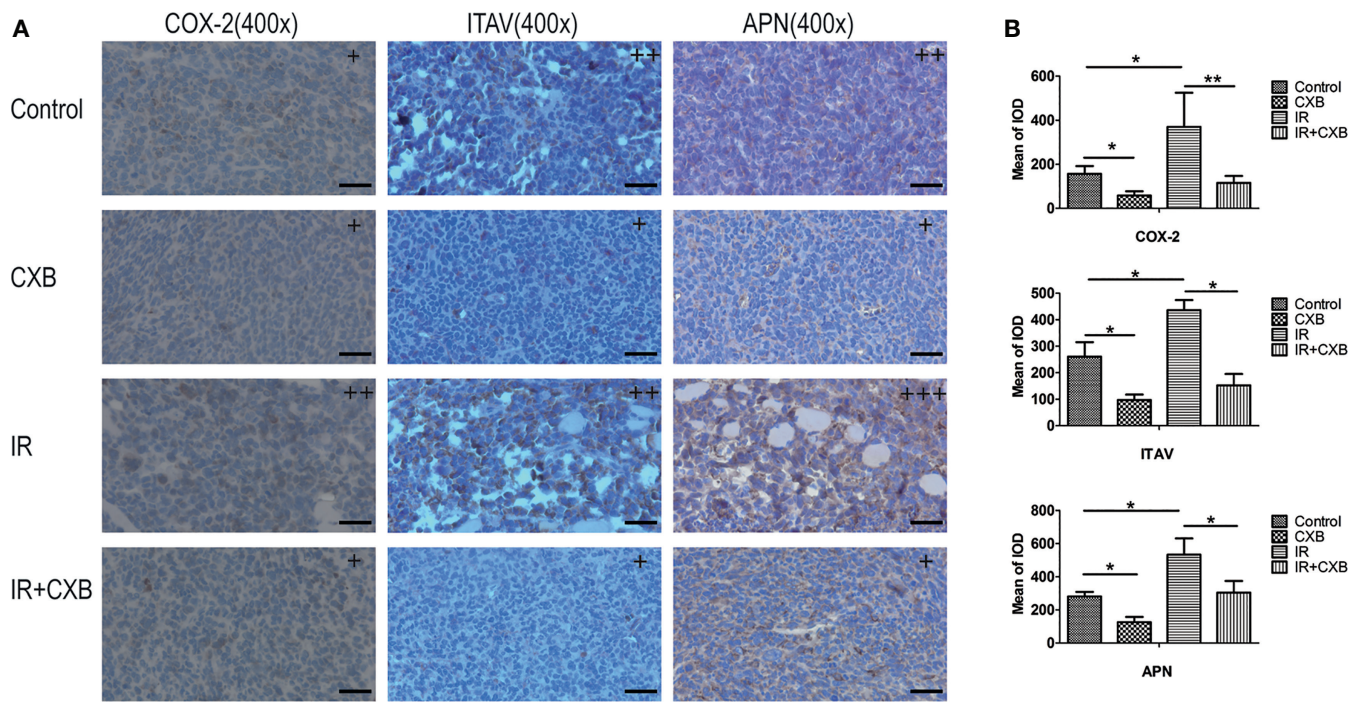

FIGURE 7 | Confirmation of off-targets of CXB in LLC xenografts. (A) The COX-2, ITAV, and APN protein expression in tumor tissues was assayed by immunohistochemistry (the control, CXB, IR, and IR plus CXB groups). The nucleus was stained blue; and the COX-2, ITAV, and APN expression were stained brown.,+++ , and +++: The subjective scores of the tissue sections by immunohistochemical staining of COX-2, APN, and ITAV, respectively. Scale bar, 300 mm. (B) The mean of IOD test (the LLC xenografts in C57 mice). ${ }^{\star} p<0.05,{ }^{\star \star} p<0.01$. CXB, celecoxib; LLC, Lewis lung cancer; COX-2, cyclooxygenase-2; ITAV, integrin alpha-V; APN, aminopeptidase N; IR, irradiation. 
First, PAS staining is not specific for VM verification. Thus, we did $\mathrm{mCD} 31 / \mathrm{hE}$-cad double staining immunofluorescence to provide direct evidence of VM formation as a quantified method. Second, the mechanism of off-targets APN and ITAV should be clarified in the future. Whether CXB acts as a specific inhibitor of APN or ITAV to inhibit VM formation needs to be explored.

\section{CONCLUSIONS}

Collectively, CXB enhances radiosensitivity in NSCLC in vitro and in vivo through inhibition of VM formation involving downregulating COX-2 and novel targets APN and ITAV. This is an off-target effect of CXB and may provide new insights into the mechanisms underlying VM formation. Our findings hold promise of an effective strategy for eliminating IR resistance in NSCLC.

\section{DATA AVAILABILITY STATEMENT}

The original contributions presented in the study are included in the article. Further inquiries can be directed to the corresponding authors.

\section{REFERENCES}

1. Suzuki K, Gerelchuluun A, Hong Z, Sun L, Zenkoh J, Moritake T, et al. Celecoxib Enhances Radiosensitivity of Hypoxic Glioblastoma Cells Through Endoplasmic Reticulum Stress. Neuro Oncol (2013) 15(9):1186-99. doi: 10.1093/neuonc/not062

2. Yang MY, Lee HT, Chen CM, Shen CC, Ma HI. Celecoxib Suppresses the Phosphorylation of STAT3 Protein and can Enhance the Radiosensitivity of Medulloblastoma-Derived Cancer Stem-Like Cells. Int J Mol Sci (2014) 15 (6):11013-29. doi: 10.3390/ijms150611013

3. Xu XT, Hu WT, Zhou JY, Tu Y. Celecoxib Enhances the Radiosensitivity of HCT116 Cells in a COX-2 Independent Manner by Up-Regulating BCCIP. Am J Transl Res (2017) 9(3):1088-100.

4. Dittmann KH, Mayer C, Ohneseit PA, Raju U, Andratschke NH, Milas L, et al. Celecoxib Induced Tumor Cell Radiosensitization by Inhibiting Radiation Induced Nuclear EGFR Transport and DNA-Repair: A COX-2 Independent Mechanism. Int J Radiat Oncol Biol Phys (2008) 70(1):203-12. doi: 10.1016/j.ijrobp.2007.08.065

5. Sobolewski C, Cerella C, Dicato M, Diederich M. Cox-2 Inhibitors Induce Early C-Myc Downregulation and Lead to Expression of Differentiation Markers in Leukemia Cells. Cell Cycle (2011) 10(17):2978-93. doi: 10.4161/ cc.10.17.16460

6. Brown JM. Vasculogenesis: A Crucial Player in the Resistance of Solid Tumours to Radiotherapy. Br J Radiol (2014) 87(1035):20130686. doi: 10.1259/bjr.20130686

7. Ahn GO, Brown JM. Influence of Bone Marrow-Derived Hematopoietic Cells on the Tumor Response to Radiotherapy: Experimental Models and Clinical Perspectives. Cell Cycle (2009) 8(7):970-6. doi: 10.4161/ cc.8.7.8075

8. Sonveaux P, Brouet A, Havaux X, Gregoire V, Dessy C, Balligand JL, et al. Irradiation-Induced Angiogenesis Through the Up-Regulation of the Nitric Oxide Pathway: Implications for Tumor Radiotherapy. Cancer Res (2003) 63 (5):1012-9.

9. Koukourakis MI. Tumour Angiogenesis and Response to Radiotherapy. Anticancer Res (2001) 21(6B):4285-300.

\section{ETHICS STATEMENT}

The animal study was reviewed and approved by the Laboratory Animal Welfare and Ethics Committee of Army Medical University.

\section{AUTHOR CONTRIBUTIONS}

$\mathrm{KN}$, XWC, and LPZ carried out the experiments. KN and XWC analyzed the data. RXL and JGS conceived and designed the experiments. KN and YQ drafted the manuscript. All authors contributed to the article and approved the submitted version.

\section{FUNDING}

This study was funded by the National Natural Science Foundation of China (Nos. 81773245, 81972858), Technology Innovation and Application Development Project of Chongqing (No. cstccxljrc201910), the Cultivation Program for Clinical Research Talents of Army Medical University in 2018 [2018XLC1010], and the Science and Technology Innovation Special Project of Chongqing Social Undertakings and Livelihood Security (No. cstc2017shmsA130108).

10. Valdivia A, Mingo G, Aldana V, Pinto MP, Ramirez M, Retamal C, et al. Fact or Fiction, It Is Time for a Verdict on Vasculogenic Mimicry? Front Oncol (2019) 9:680. doi: 10.3389/fonc.2019.00680

11. Ribatti D, Pezzella F. Overview on the Different Patterns of Tumor Vascularization. Cells (2021) 10(3):639. doi: 10.3390/cells10030639

12. Siegel RL, Miller KD, Fuchs HE, Jemal A. Cancer Statistics, 2021. CA Cancer J Clin (2021) 71(1):7-33. doi: 10.3322/caac.21654

13. Paracha N, Abdulla A, MacGilchrist KS. Systematic Review of Health State Utility Values in Metastatic Non-Small Cell Lung Cancer With a Focus on Previously Treated Patients. Health Qual Life Outc (2018) 16(1):179. doi: 10.1186/s12955-018-0994-8

14. Youn H, Son B, Kim W, Jun SY, Lee JS, Lee JM, et al. Dissociation of MIFRps3 Complex and Sequential NF- $\kappa b$ Activation Is Involved in IR-Induced Metastatic Conversion of NSCLC. J Cell Biochem (2015) 116(11):2504-16. doi: $10.1002 / j \mathrm{jb} .25195$

15. Kim W, Youn H, Kang C, Youn B. Inflammation-Induced Radioresistance Is Mediated by ROS-Dependent Inactivation of Protein Phosphatase 1 in NonSmall Cell Lung Cancer Cells. Apoptosis (2015) 20(9):1242-52. doi: 10.1007/ s10495-015-1141-1

16. Xia Y, Cai XY, Fan JQ, Zhang LL, Ren JH, Li ZY, et al. The Role of Sema4d in Vasculogenic Mimicry Formation in Non-Small Cell Lung Cancer and the Underlying Mechanisms. Int J Cancer (2019) 144(9):2227-38. doi: 10.1002/ ijc. 31958

17. Yao L, Zhang D, Zhao X, Sun B, Liu Y, Gu Q, et al. Dickkopf-1-Promoted Vasculogenic Mimicry in Non-Small Cell Lung Cancer Is Associated With EMT and Development of a Cancer Stem-Like Cell Phenotype. J Cell Mol Med (2016) 20(9):1673-85. doi: 10.1111/jcmm.12862

18. Zhou X, Gu R, Han X, Wu G, Liu J. Cyclin-Dependent Kinase 5 Controls Vasculogenic Mimicry Formation in Non-Small Cell Lung Cancer via the FAK-AKT Signaling Pathway. Biochem Biophys Res Commun (2017) 492 (3):447-52. doi: 10.1016/j.bbrc.2017.08.076

19. Wagenblast E, Soto M, Gutiérrez-Ángel S, Hartl CA, Gable AL, Maceli AR, et al. A Model of Breast Cancer Heterogeneity Reveals Vascular Mimicry as a Driver of Metastasis. Nature (2015) 520(7547):358-62. doi: 10.1038/ nature 14403 
20. Angara K, Borin TF, Rashid MH, Lebedyeva I, Ara R, Lin PC, et al. CXCR2Expressing Tumor Cells Drive Vascular Mimicry in Antiangiogenic TherapyResistant Glioblastoma. Neoplasia (New York NY) (2018) 20(10):1070-82. doi: 10.1016/j.neo.2018.08.011

21. Wang Y, Yang R, Wang X, Ci H, Zhou L, Zhu B, et al. Evaluation of the Correlation of Vasculogenic Mimicry, Notch4, DLL4, and KAI1/CD82 in the Prediction of Metastasis and Prognosis in Non-Small Cell Lung Cancer. Med (Baltimore) (2018) 97(52):e13817. doi: 10.1097/MD.0000000000013817

22. Song $\mathrm{H}, \mathrm{Ci} \mathrm{H}, \mathrm{XuJ}$, Xu Z, Zhang Y, Wang Y, et al. Vasculogenic Mimicry and Expression of Slug and Vimentin Correlate With Metastasis and Prognosis in Non-Small Cell Lung Cancer. Int J Clin Exp Pathol (2018) 11(5):2749-58.

23. Zhou Q, Zhou CC, Chen GY, Cheng Y, Huang C, Zhang L, et al. A Multicenter Phase II Study of Sorafenib Monotherapy in Clinically Selected Patients With Advanced Lung Adenocarcinoma After Failure of EGFR-TKI Therapy (Chinese Thoracic Oncology Group, CTONG 0805). Lung Cancer (Amsterdam Netherlands) (2014) 83(3):369-73. doi: 10.1016/j.lungcan.2013.12.014

24. Fornari F, Giovannini C, Piscaglia F, Gramantieri L. Elucidating the Molecular Basis of Sorafenib Resistance in HCC: Current Findings and Future Directions. J Hepatocell Carcinoma (2021) 8:741-57. doi: 10.2147/jhc.S285726

25. Pezzella F, Ribatti D. Vascular Co-Option and Vasculogenic Mimicry Mediate Resistance to Antiangiogenic Strategies. Cancer Rep (Hoboken NJ) (2020) e1318. doi: $10.1002 / \mathrm{cnr} 2.1318$

26. Wang H, Lin H, Pan J, Mo C, Zhang F, Huang B, et al. Vasculogenic Mimicry in Prostate Cancer: The Roles of EphA2 and PI3K. J Cancer (2016) 7(9):111424. doi: 10.7150/jca.14120

27. Xu X, Zong Y, Gao Y, Sun $\mathrm{X}$, Zhao H, Luo W, et al. VEGF Induce Vasculogenic Mimicry of Choroidal Melanoma Through the PI3k Signal Pathway. BioMed Res Int (2019) 2019:3909102. doi: 10.1155/2019/ 3909102

28. Rong X, Huang B, Qiu S, Li X, He L, Peng Y. Tumor-Associated Macrophages Induce Vasculogenic Mimicry of Glioblastoma Multiforme Through Cyclooxygenase-2 Activation. Oncotarget (2016) 7(51):83976-86. doi: 10.18632/ oncotarget.6930

29. Ju RJ, Li XT, Shi JF, Li XY, Sun MG, Zeng F, et al. Liposomes, Modified With PTD(HIV-1) Peptide, Containing Epirubicin and Celecoxib, to Target Vasculogenic Mimicry Channels in Invasive Breast Cancer. Biomaterials (2014) 35(26):7610-21. doi: 10.1016/j.biomaterials.2014.05.040

30. Ju RJ, Zeng F, Liu L, Mu LM, Xie HJ, Zhao Y, et al. Destruction of Vasculogenic Mimicry Channels by Targeting Epirubicin Plus Celecoxib Liposomes in Treatment of Brain Glioma. Int J Nanomed (2016) 11:113146. doi: 10.2147/IJN.S94467

31. Li W, Ruan W, Peng Y, Wang D. Soy and the Risk of Type 2 Diabetes Mellitus: A Systematic Review and Meta-Analysis of Observational Studies. Diabetes Res Clin Pract (2018) 137:190-9. doi: 10.1016/j.diabres.2018.01.010

32. Park W, Oh YT, Han JH, Pyo H. Antitumor Enhancement of Celecoxib, A Selective Cyclooxygenase-2 Inhibitor, in a Lewis Lung Carcinoma Expressing Cyclooxygenase-2. J Exp Clin Cancer Res (2008) 27:66. doi: 10.1186/17569966-27-66

33. Liu ZJ, Zhou YJ, Ding RL, Xie F, Fu SZ, Wu JB, et al. In Vitro and In Vivo Apatinib Inhibits Vasculogenic Mimicry in Melanoma MUM-2B Cells. PloS One (2018) 13(7):e0200845. doi: 10.1371/journal.pone.0200845

34. Wang X, Cheng L, Xie HJ, Ju RJ, Xiao Y, Fu M, et al. Functional Paclitaxel Plus Honokiol Micelles Destroying Tumour Metastasis in Treatment of NonSmall-Cell Lung Cancer. Artif Cells Nanomed Biotechnol (2018) 46 (sup2):1154-69. doi: 10.1080/21691401.2018.1481082

35. Xie HJ, Zhao J, Zhuo-Ma D, Zhan-Dui N, Er-Bu A, Tsering T. Inhibiting Tumour Metastasis by DQA Modified Paclitaxel Plus Ligustrazine Micelles in Treatment of Non-Small-Cell Lung Cancer. Artif Cells Nanomed Biotechnol (2019) 47(1):3465-77. doi: 10.1080/21691401.2019.1653900

36. Wang Y, Fu M, Liu J, Yang Y, Yu Y, Li J, et al. Inhibition of Tumor Metastasis by Targeted Daunorubicin and Dioscin Codelivery Liposomes Modified With PFV for the Treatment of Non-Small-Cell Lung Cancer. Int J Nanomed (2019) 14:4071-90. doi: 10.2147/IJN.S194304

37. Roh JL, Sung MW, Park SW, Heo DS, Lee DW, Kim KH. Celecoxib can Prevent Tumor Growth and Distant Metastasis in Postoperative Setting. Cancer Res (2004) 64(9):3230-5. doi: 10.1158/0008-5472.can-03-3050

38. Abou-Issa H, Alshafie G. Celecoxib: A Novel Treatment for Lung Cancer. Expert Rev Anticancer Ther (2004) 4(5):725-34. doi: 10.1586/14737140.4.5.725
39. Choy H, Milas L. Enhancing Radiotherapy With Cyclooxygenase-2 Enzyme Inhibitors: A Rational Advance? J Natl Cancer Inst (2003) 95(19):1440-52. doi: $10.1093 /$ jnci/djg058

40. Sun J, Liu NB, Zhuang HQ, Zhao LJ, Yuan ZY, Wang P. Celecoxib-Erlotinib Combination Treatment Enhances Radiosensitivity in A549 Human Lung Cancer Cell. Cancer Biomark (2017) 19(1):45-50. doi: 10.3233/CBM-160323

41. Jin YH, Li WH, Bai Y, Ni L. Efficacy of Erlotinib and Celecoxib for Patients With Advanced Non-Small Cell Lung Cancer: A Retrospective Study. Med (Baltimore) (2019) 98(10):e14785. doi: 10.1097/MD.0000000000014785

42. Schonthal AH. Exploiting Cyclooxygenase-(in)Dependent Properties of COX2 Inhibitors for Malignant Glioma Therapy. Anticancer Agents Med Chem (2010) 10(6):450-61. doi: 10.2174/1871520611009060450

43. Sobolewski C, Rhim J, Legrand N, Muller F, Cerella C, Mack F, et al. 2,5Dimethyl-Celecoxib Inhibits Cell Cycle Progression and Induces Apoptosis in Human Leukemia Cells. J Pharmacol Exp Ther (2015) 355(2):308-28. doi: 10.1124/jpet.115.225011

44. Saiki I, Fujii H, Yoneda J, Abe F, Nakajima M, Tsuruo T, et al. Role of Aminopeptidase N (CD13) in Tumor-Cell Invasion and Extracellular Matrix Degradation. Int J Cancer (1993) 54(1):137-43. doi: 10.1002/ijc.2910540122

45. Fujii H, Nakajima M, Aoyagi T, Tsuruo T. Inhibition of Tumor Cell Invasion and Matrix Degradation by Aminopeptidase Inhibitors. Biol Pharm Bull (1996) 19(1):6-10. doi: 10.1248/bpb.19.6

46. Pasqualini R, Koivunen E, Kain R, Lahdenranta J, Sakamoto M, Stryhn A, et al. Aminopeptidase $\mathrm{N}$ Is a Receptor for Tumor-Homing Peptides and a Target for Inhibiting Angiogenesis. Cancer Res (2000) 60(3):722-7.

47. Bhagwat SV, Lahdenranta J, Giordano R, Arap W, Pasqualini R, Shapiro LH. CD13/APN Is Activated by Angiogenic Signals and Is Essential for Capillary Tube Formation. Blood (2001) 97(3):652-9. doi: 10.1182/blood.v97.3.652

48. Murakami H, Yokoyama A, Kondo K, Nakanishi S, Kohno N, Miyake M. Circulating Aminopeptidase N/CD13 Is an Independent Prognostic Factor in Patients With Non-Small Cell Lung Cancer. Clin Cancer Res (2005) 11 (24 Pt 1):8674-9. doi: 10.1158/1078-0432.CCR-05-1005

49. Zhang Q, Wang J, Zhang H, Zhao D, Zhang Z, Zhang S. Expression and Clinical Significance of Aminopeptidase N/CD13 in Non-Small Cell Lung Cancer. J Cancer Res Ther (2015) 11(1):223-8. doi: 10.4103/0973-1482.138007

50. Tome $\mathrm{Y}$, Kiyuna $\mathrm{T}$, Uehara F, Bouvet M, Tsuchiya $\mathrm{H}$, Kanaya F, et al. Imaging the Interaction of Alphav Integrin-GFP in Osteosarcoma Cells With RFPExpressing Host Stromal Cells and Tumor-Scaffold Collagen in the Primary and Metastatic Tumor Microenvironment. J Cell Biochem (2019) 120(1):2839. doi: $10.1002 / j \mathrm{cb} .27353$

51. Ciardiello C, Leone A, Lanuti P, Roca MS, Moccia T, Minciacchi VR, et al. Large Oncosomes Overexpressing Integrin Alpha-V Promote Prostate Cancer Adhesion and Invasion via AKT Activation. J Exp Clin Cancer Res (2019) 38 (1):317. doi: 10.1186/s13046-019-1317-6

52. Camorani S, Crescenzi E, Gramanzini M, Fedele M, Zannetti A, Cerchia L. Aptamer-Mediated Impairment of EGFR-Integrin Alphavbeta3 Complex Inhibits Vasculogenic Mimicry and Growth of Triple-Negative Breast Cancers. Sci Rep (2017) 7:46659. doi: 10.1038/srep46659

53. Hitzerd SM, Verbrugge SE, Ossenkoppele G, Jansen G, Peters GJ. Positioning of Aminopeptidase Inhibitors in Next Generation Cancer Therapy. Amino Acids (2014) 46(4):793-808. doi: 10.1007/s00726-013-1648-0

54. Schmidt LH, Brand C, Stucke-Ring J, Schliemann C, Kessler T, Harrach S, et al. Potential Therapeutic Impact of CD13 Expression in Non-Small Cell Lung Cancer. PLoS One (2017) 12(6):e0177146. doi: 10.1371/journal. pone. 0177146

55. Thompson EM, Whitney NL, Wu YJ, Neuwelt EA. The Effect of Alpha-V Integrin Inhibition on the Malignant Characteristics of Medulloblastoma. J Neurosurg Pediatr (2013) 11(1):60-7. doi: 10.3171/2012.9.PEDS12268

56. Wu YJ, Muldoon LL, Gahramanov S, Kraemer DF, Marshall DJ, Neuwelt EA. Targeting alphaV-Integrins Decreased Metastasis and Increased Survival in a Nude Rat Breast Cancer Brain Metastasis Model. J Neurooncol (2012) 110 (1):27-36. doi: 10.1007/s11060-012-0942-0

57. Ning S, Tian J, Marshall DJ, Knox SJ. Anti-Alphav Integrin Monoclonal Antibody Intetumumab Enhances the Efficacy of Radiation Therapy and Reduces Metastasis of Human Cancer Xenografts in Nude Rats. Cancer Res (2010) 70(19):7591-9. doi: 10.1158/0008-5472.CAN-10-1639

58. Chen Q, Manning CD, Millar H, McCabe FL, Ferrante C, Sharp C, et al. CNTO 95, a Fully Human Anti Alphav Integrin Antibody, Inhibits Cell 
Signaling, Migration, Invasion, and Spontaneous Metastasis of Human Breast Cancer Cells. Clin Exp Metastasis (2008) 25(2):139-48. doi: 10.1007/s10585007-9132-4

Conflict of Interest: The authors declare that the research was conducted in the absence of any commercial or financial relationships that could be construed as a potential conflict of interest.

Publisher's Note: All claims expressed in this article are solely those of the authors and do not necessarily represent those of their affiliated organizations, or those of the publisher, the editors and the reviewers. Any product that may be evaluated in this article, or claim that may be made by its manufacturer, is not guaranteed or endorsed by the publisher.

Copyright (C) $2021 \mathrm{Niu}$, Chen, Qin, Zhang, Liao and Sun. This is an open-access article distributed under the terms of the Creative Commons Attribution License (CC BY). The use, distribution or reproduction in other forums is permitted, provided the original author(s) and the copyright owner(s) are credited and that the original publication in this journal is cited, in accordance with accepted academic practice. No use, distribution or reproduction is permitted which does not comply with these terms. 